Arteterapia. Papeles de arteterapia y educación para inclusión social ISSN-e 1988-8309

http://dx.doi.org/10.5209/ARTE.57576

\title{
Del abismo a las raíces. Análisis y reflexión sobre el tratamiento de un caso de abuso sexual con psicoterapia y arteterapia
}

\author{
Pilar Ascaso Palacín ${ }^{1}$
}

Recibido: 17 de julio/ Aceptado: 24 de Julio

Resumen. Se presenta en síntesis el proceso de psico-arteterapia realizado con un varón, adulto, víctima de abuso sexual durante varios años en su adolescencia. Explorando la dimensión del trauma el paciente puede atravesar su visión de 'víctima' para enfrentarse a otras verdades ocultas más profundas de su historia personal. Veremos algunas propuestas de arteterapia que han sido significativas en su evolución y finalmente haremos algunas reflexiones en torno al proceso y a la relación paciente-terapeuta. Palabras clave: psicoterapia; arteterapia; abuso sexual; trauma; resiliencia.

\section{[en] Out of the abyss / From the depths of the problem to its very roots. analysis and observations for the treatment of sexual abuse using psychotherapy and art therapy}

Abstract. In short, using psycho-art therapy in the case of a male adult, who suffered continued sexual abuse during his adolescence. By exploring the different traumas experienced by the patient, he can overcome his "victim" status in order to confront other, deeper and more hidden truths regarding his personal history. We will examine some art therapy techniques which have contributed to his positive evolution and make some observations regarding the methodology used and the relationship between patient and therapist.

Key words: psychotherapy; art therapy; sexual abuse; trauma; resilience.

Sumario: 1. Introducción. 2. Historia clínica y exploración etapa abusos sexuales. 3. Exploración de la época de su infancia. 4. Exploración de la identidad. 5. Definición de Abuso Sexual. 6. Secuelas del abuso sexual. 7. Los talleres grupales de arteterapia. 8. Trabajo con la comprensión y el perdón. 9. Conclusiones. 10. Algunas reflexiones. 11. Bibliografía.

Cómo citar: Ascaso Palacín, P. (2017). Del abismo a las raíces. Análisis y reflexión sobre el tratamiento de un caso de abuso sexual con psicoterapia y arteterapia, en Arteterapia. Papeles de arteterapia y educación para inclusión social 12, 257-275. 


\section{Introducción}

Los abusos sexuales a menores es un tema todavía muy tabú en nuestra sociedad, que se mueve mayoritariamente de forma secreta en los subterráneos de la vida familiar, escolar y laboral. Según Save The Children (2001: 23-24), se calcula que sólo se conocen entre el 10-20 por cien de los casos reales. Es lo que se llama el vértice de la pirámide de maltrato. Además se estima que el 23 por cien de las niñas y un 15 por cien de los niños sufren abusos sexuales antes de los 17 años en España. La Convención de Naciones Unidas de 1989 sobre los Derechos de los Niños ha sido un marco de referencia importante que ha ayudado a destaparlo y movilizarlo en las dos últimas décadas.

El caso que aquí se presenta es un reflejo de esta realidad. Veremos cómo un adulto cercano al ambiente familiar se gana la confianza de un menor. El menor, que tiene problemas emocionales y es especialmente sensible y vulnerable, queda atrapado en esta situación, la cual se va complicando de tal forma a lo largo del tiempo que acaba consolidando una actitud vital peligrosamente autodestructiva. Muchos años después, ya al límite de sus fuerzas, decide pedir ayuda psiquiátrica y psicológica.

En el camino del acompañamiento psico-arteterapéutico el paciente puede adentrarse en la experiencia interior del abuso sexual sufrido, explorar la dimensión del trauma, observar los efectos devastadores de esta violencia prolongada, y analizar cómo condiciona en profundidad su universo mental, emocional y físico en su vida de adulto.

A medida que transita por este camino, se abren otras posibilidades de ampliar la visión de su historia de vida que le permiten ir más allá, enfrentarse a sí mismo, y poder entender la motivación profunda de su enfermedad mental y del bloqueo generalizado que sufre, que a su vez ha contribuido a ocultar y agravar otros problemas de su personalidad que ya padecía antes de los abusos.

A lo largo del proceso terapéutico se han combinado las sesiones de terapia individual con sesiones de arteterapia grupal. De estas sesiones he seleccionado algunos trabajos de arteterapia que han resultado muy significativos en su evolución personal. Imágenes y metáforas que nos han permitido entrar en un mundo interior en principio muy cerrado, y que poco a poco va abriéndose a la expresión, a la toma de conciencia, a la reflexión y al cambio. Todo ello nos llevará a destacar una serie de conclusiones y finalmente incorporaremos algunas reflexiones.

\section{Historia clínica y exploración etapa abusos sexuales}

Juan (nombre ficticio) tiene 46 años cuando inicia psicoterapia. Se encuentra en tratamiento psiquiátrico, con dos diagnósticos: 'Depresión mayor con ideas autolíticas' y 'Brote neurótico con pérdida momentánea de la conciencia de la realidad y obsesión compulsiva autodestructiva'. Ha intentado suicidarse en varias ocasiones y también se ha realizado autolesiones. Está de baja laboral y toma tres antidepresivos distintos que combina con tranquilizantes, lo cual le produce una dificultad para pensar y expresarse verbalmente. 
En las primeras sesiones no para de llorar compulsivamente y se expresa de forma muy desordenada y confusa. Su demanda inicial es que no puede más y necesita ayuda. Se siente literalmente 'hundido, sin fuerzas, y sólo desea morirse o desaparecer'. Poco a poco Juan consigue hilar su relato. Comenta que arrastra un secreto que no había contado antes a nadie, refiriéndose a los abusos sexuales que estuvo sufriendo de los 13 a los 18 años. El agresor, -le llamaremos señor X-, era un hombre, empleado apreciado de la empresa de su familia que anteriormente había sido religioso y docente. Por mediación de un familiar empieza a trabajar con él y a pesar de la gran diferencia de edad se hacen muy amigos. Juan se siente estimado, escuchado, comprendido, y desarrolla una gran confianza y afecto hacia el señor X. Debido a esto la relación se estrecha de tal forma que, aparte del lugar de trabajo, se empiezan a ver en la vivienda del señor X, donde pasan horas los dos solos. En un momento dado descubre que $\mathrm{X}$ es homosexual y poco después empiezan los abusos.

La primera vez que el señor X le toca por sorpresa Juan queda paralizado, como en shock. A partir de ahí algo se le rompe por dentro y ya nada es igual. Se siente dominado por $\mathrm{X}$ y las prácticas sexuales se convierten en un ritual secreto, que se repiten semanalmente. A los 15 años, los padres le llevaron al psiquiatra, porque le veían muy mal, pero no pudo explicar lo que le pasaba. Juan tiene la sensación de vivir esos años 'como en un túnel oscuro'. Se siente bloqueado, perdido, lleno de culpa y vergüenza, sin salida. Le propongo que refleje esto que comenta en un dibujo y dedicamos varias sesiones a explorar las sensaciones físicas y emocionales que le produce esta imagen.

Posteriormente surge otra metáfora que nos permite seguir ahondando por este camino. Juan, en su situación de 'parálisis' ante el señor X, crea una coraza interior, una armadura, para blindarse, protegerse de él. Quiere demostrarle con ello que no le gusta lo que pasa, que simplemente lo soporta, aunque a la vez sí siente placer, lo cual le confunde y hunde más. Siente asco, rechazo, pero se deja hacer de forma sumisa durante varios años. Esa coraza de rigidez todavía se le activa actualmente en diferentes circunstancias, especialmente en las escasas relaciones sexuales que ha intentado mantener con su pareja, y que se han ido extinguiendo por falta de estímulos mutuos, y también en las relaciones personales donde hay algún contacto físico.

Trabajamos con la metáfora de la armadura: 'Visualiza la armadura, qué forma tiene, cómo es, de qué está hecha, siéntela en tu cuerpo, cómo presiona, cómo respiras dentro de ella... dibújala’. ¿Qué quieres hacer con ella? ¿Puedes visualizar alguna forma de desprenderte?, ¿Cómo te sientes al quitártela? ¿Cómo es no llevarla puesta? ¿Cómo respiras ahora? ¿Cómo sería tu vida sin la armadura? 


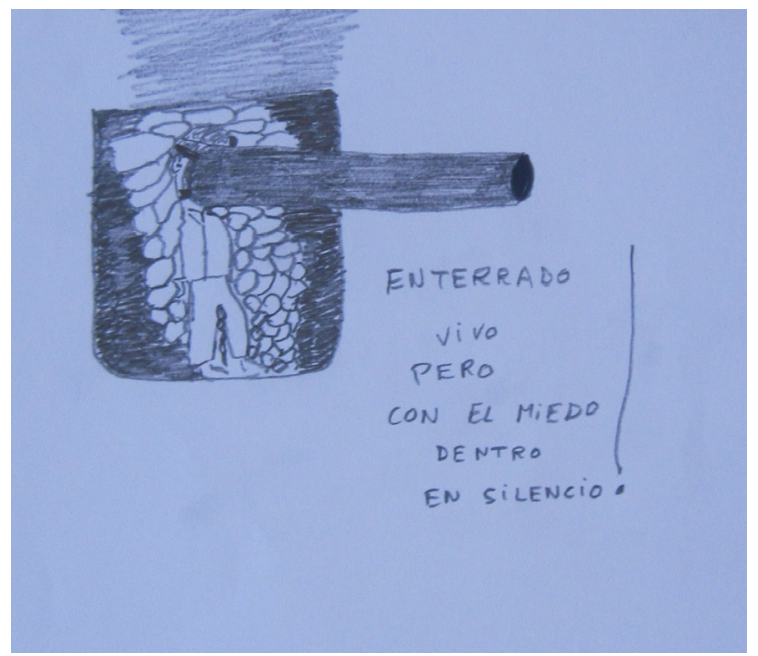

Dibujo 'Como en un túnel oscuro'

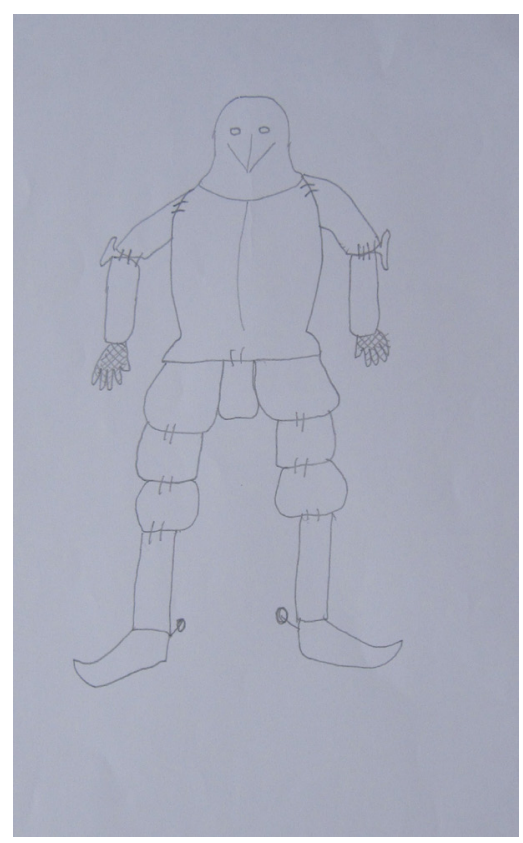

/Dibujo 'La armadura'

Según se va consolidando la confianza en el proceso, Juan puede enfrentarse a una verdad que le cuesta mucho reconocer, debido a que la situación de abusos se mantuvo durante 13 años. Tenía 26 años cuando decide cortar estas prácticas con X, a raíz de conocer a una chica, aunque continúan viéndose y manteniendo la relación de 'amigos', -tal como todo el mundo les veía-, hasta la muerte de X, pues se dedica a cuidarle hasta el final de su enfermedad.

El hecho de mantener esta relación de sumisión durante tanto tiempo le crea una confusión mental y una visión de sí mismo devastadora. No entiende cómo llegó a 
esta situación, cómo se quedó junto a su violentador durante 25 años, aguantando algo que era horrible para él. Tras la muerte de X, sigue llevando una doble vida secreta. Dedica años a ver pornografía por internet. No hay vida digna para él. Se siente tan sucio que sólo puede vivir en la oscuridad, en soledad, y se encierra en su casa fuera del horario de trabajo. Tiene la sensación de 'vivir permanentemente al borde de un abismo donde puede caer y perderse definitivamente en cualquier momento'.

Intentar comprender lo incomprensible para él pasa por poner nombre a lo que lleva dentro, observar qué tipo de relato interior se ha ido construyendo, explorar cómo le afecta en su visión de sí mismo y de sus relaciones con el exterior. Va transitando por diferentes estados emocionales de rabia, odio, pena, desesperación.... A medida que avanza en su historia de vida puede vislumbrar más claramente los motivos por los que se sometió pasivamente a esta situación de abusos durante tantos años. Se hace más consciente de cómo su visión de 'víctima de abusos sexuales' le impide encontrar respuestas honestas y valientes sobre otros aspectos de su persona que han ido quedando en un confuso segundo plano, escondidos en lo más remoto de su interior.

En una sesión individual, mediante una relajación, le propongo visualizar un lugar que sea seguro para él, donde poder refugiarse si lo necesita. Él imagina una playa preciosa donde suele ir a bañarse, pero la ve sucia, y no puede sentirse a gusto. 'Es el reflejo de la suciedad que lo impregna todo en su interior', dice. Le pido que la dibuje y le destaco el hecho de que, a pesar de la suciedad que lo impregna todo, 'la belleza de ese paisaje sigue intacta'. Le pregunto qué haría si se encontrara esa playa real que tanto le gusta verdaderamente sucia: -'Me pondría a limpiarla y no pararía hasta que estuviera limpia-’. ¿Y cómo lo harías? - 'Con una excavadora con pala-’. Le pido que la dibuje. ‘Puedes visualizarte limpiando la playa con la excavadora?’,.. ‘ ¿Cómo percibes la playa ahora?': - 'Ha quedado casi limpia, pero aún hay un pedrusco en medio de la playa, enorme, muy duro, que no he podido sacar, y no tocaría estar ahi porque crea disarmonía en el paisaje-’. ¿Cómo es ese pedrusco? 'Dibújalo'.

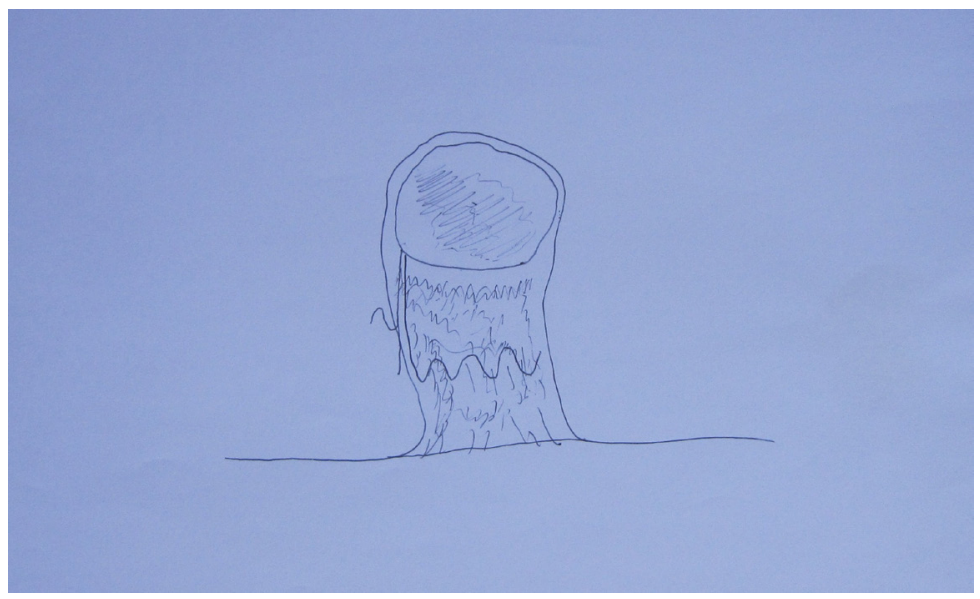

Dibujo 'El pedrusco en la playa'

Esta imagen nos da material para seguir trabajando lo que significa la forma del pedrusco, tan evidente, relacionarla con los otros signos fálicos de sus dibujos anteriores y explorar sus dificultades para sacar este pedrusco, teniendo una excavadora tan potente. 


\section{Exploración de la época de su infancia.}

$\mathrm{Al}$ adentrarnos en la época de su infancia, anterior a los abusos, Juan se describe como un niño diferente, tímido, solitario, inseguro, extremadamente sensible y sumiso, triste, celoso de sus hermanos. Padeció encopresis hasta los 12 años. Fue a raíz de un hecho traumático con su abuela cuando tenía 4 años. A partir de ahí era incapaz de ir al baño mientras hubiera gente alrededor. En su casa y en el colegio lo pasó muy mal durante años por este motivo, pues a veces no podía evitar evacuar en los pantalones. Por el olor lo notaban los demás y se mofaban de él, le insultaban y no podía defenderse, completamente avergonzado y bloqueado. Como consecuencia no quería ir al colegio, suspendía mucho, no se integraba, era una tortura que le producía dolor de estómago, ansiedad insoportable y se ponía enfermo con frecuencia.

Le propongo que dibuje ese niño. Dibuja sólo desde la cintura para arriba y sin manos. 'Ponle voz a este niño, cómo se siente, qué quiere expresar, qué necesita'. Exploramos qué pasa con las partes del cuerpo que no dibuja. Se permite reconocer que ese niño en realidad sentía un cierto placer haciéndoselo encima, aunque también se sintiera horriblemente mal. Era su forma de manejar la negatividad que llevaba dentro, su forma de llamar la atención. También pasaba de un extremo a otro, a no evacuar durante días y crear así otro problema. Carta del adulto al niño:

Este niño me da pena, necesita un abrazo de su madre y un darle ánimos tranquilo y sereno de su padre. Necesita que le toquen y le dejen tener iniciativa, y también que le vigilen queriéndole muchísimo... Necesita seguridad y experimentar, leer, dibujar ... necesita alegría y crecer sin ataduras, necesita un mimo por la mañana. Tiene miedo de la escuela, de la ciudad, con tanto ruido. Le gusta el silencio, ser bueno y ser más niño más tiempo, muchísimo más tiempo... no sigas yendo a la escuela, yo te enseñaré... Yo siempre estaréa tu lado, y si no, las montañas..Deja morirte, si ves que no puedes vivir, que yo te ayudaré... Estáte tranquilo, no hables si no quieres, que yo te miro. Llora, llora y llora... Vive y mira los animales, cariñosos como tú. Vive cada momento, no tengas miedo porque un día serás tú y yo lo estaré viendo, cerca de ti.

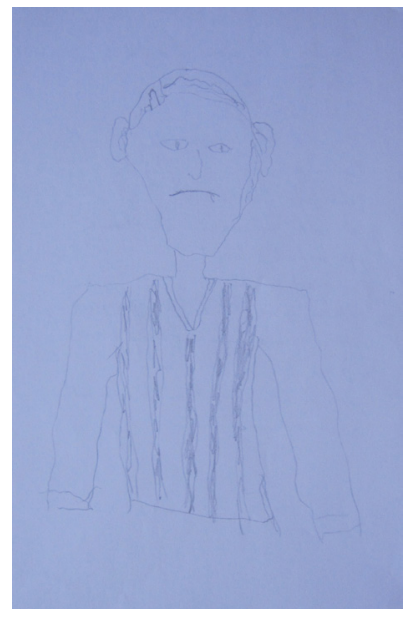

Dibujo 'El niño' 


\section{Exploración de la identidad.}

En general su autoimagen y autoconcepto se mantienen en la línea que había descrito de su infancia. Se percibe a sí mismo como depresivo, con emociones y pensamientos negativos, sentimientos de inferioridad, convencido de que nunca saldrá de esta oscuridad, de su tendencia al masoquismo, a la sumisión. No consigue destacar nada positivo de su persona.

Trabajando con la visualización de un rosal como forma proyectiva de representarse a sí mismo, le surgen sensaciones de estar en un lugar cerrado, empedrado/ enladrillado, un cercado que le separa totalmente del resto del mundo. La tierra es buena pero está en una maceta mínima que le dificulta crecer, le faltan las hojas protectoras y muestra las espinas descarnadas. Vemos qué le está diciendo este rosal de sí mismo. Qué le pasa, qué necesita este rosal. Al relacionarlo con su dibujo de la visión en túnel, puede entender algunas cosas de sí mismo.

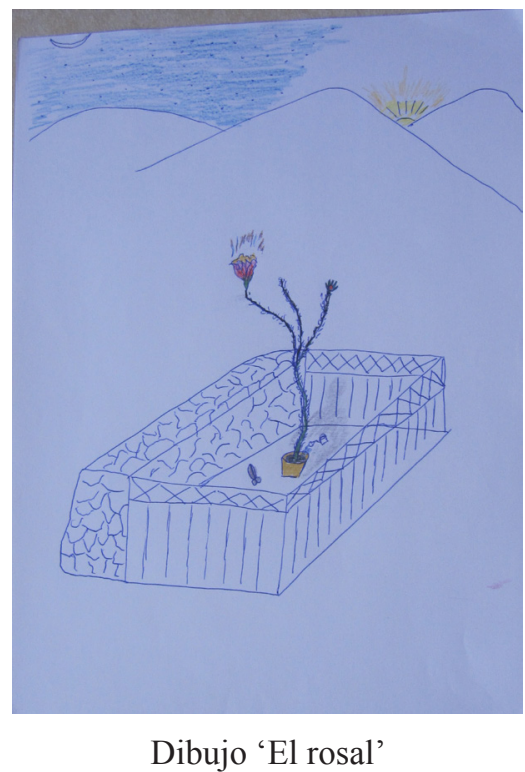

Vamos viendo también que vive en un continuo flujo de pensamientos obsesivo-compulsivos de cariz destructivo: no puede mirar a los ojos de las personas porque se siente muy sucio y cree que los demás se lo ven en la mirada; tiene recuerdos frecuentes de escenas sexuales vividas con X; pensamientos persistentes de temor a acabar siendo él también un potencial abusador/pederasta de menores; ideas frecuentes de lesionarse o de suicidio; algunas conductas anormales, etc.

Igualmente padece una fuerte adicción a la pornografía, iniciada a raíz de los vídeos y revistas pornográficas que empezó a visionar en casa de $\mathrm{X}$ y en su compañía. Se pasa varias horas diarias y fines de semana encerrado visionando películas. Durante un tiempo acudía también a los clubs de prostitución.

En el ámbito relacional tiene serias dificultades, tanto a nivel de pareja, como familiares, laborales, o sociales. Ya desde la niñez tiene un sentimiento de indefensión muy fuerte ante el mundo, que se traduce en un miedo permanente a que le hagan daño. Fuera de su casa suele sentirse alterado, ansioso, inseguro. 
En relación a su identidad sexual, Juan se percibe como heterosexual. Está casado con una mujer, pero a medida que ahondamos en el tema surgen las dudas ¿cuál es su orientación realmente, es hetero / bisexual / homosexual? En realidad no sabe cuál es su verdad, se siente confuso, y empieza a comprender que puede haber otras complejidades a las que nunca se había podido enfrentar. Va 'descubriendo' que ha tenido y tiene pensamientos de cariz homosexual, y también tuvo alguna historia sexual esporádica con hombres, que de alguna forma su mente 'registraba' como algo forzado, no buscado por él y, por tanto, 'como algo a olvidar'.

Entrando más en el tema surgen una serie de factores que le alimentan este estado de confusión. Por un lado, tiene un sistema de creencias profundas que le producen un rechazo visceral a la homosexualidad, o mejor dicho, a la idea de reconocer que él lo pudiera ser. Por otro lado, en la época de los abusos sexuales experimentaba sensaciones fuertes contrapuestas, como un sentimiento de repugnancia y asco mientras duraban esos actos, y a la vez placer físico. Asimismo, por el hecho de haber visionado tan enorme carga de pornografía desde los 13 años, su percepción de lo sexual está fuertemente condicionada por las imágenes y le cuesta diferenciar la fantasía de su realidad cotidiana. Parece que hay una fuerte disociación entre su identidad real y la que se ha ido creando artificialmente, de forma que se queda a medio camino de cualquier determinación sexual, sin poder sentirse de ninguna opción en particular, pero 'actuando' como si fuera heterosexual.

\section{Definición de Abuso Sexual}

Recogiendo los datos que van surgiendo, tanto de la historia de los abusos sexuales sufridos por Juan, como de su personalidad y sus circunstancias posteriores, podemos hacer una revisión de las secuelas detectadas que se han derivado de esta situación, y para contextualizarlo partiremos de los siguientes conceptos de abuso sexual que para el caso que nos ocupa, juntos aportan una visión más completa. De las muchas definiciones de abuso sexual que existen, los especialistas coinciden en utilizar mayoritariamente la del National Center of Child Abuse and Neglect, de 1978, al referirse a ello como '... Los contactos e interacciones entre un niño y un adulto, cuando el adulto (agresor) usa al menor para estimularse sexualmente él mismo, al menor o a otra persona. El abuso sexual puede ser también cometido por una persona menor de 18 años cuando ésta es significativamente mayor que el menor (víctima) o cuando el agresor está en una posición de poder o control sobre otro'.

En la mayoría de las definiciones se establecen dos criterios para hablar de abuso: 1) Coerción. El agresor utiliza la situación de poder que tiene para interactuar sexualmente con el menor, y 2) Asimetría de edad. El agresor es significativamente mayor que la víctima, no necesariamente mayor de edad. En relación a esta asimetría de edad, Félix López y Amaia del Campo, (2001: 15) señalan que:

En realidad, esta asimetría de edad determina muchas otras asimetrías: asimetría anatómica, asimetría en el desarrollo y especificación del deseo sexual (que no se especifica ni se consolida hasta la adolescencia), asimetría de afectos sexuales (el fenómeno de la atracción en prepúberes tiene menos connotaciones sexuales), asimetría en las habilidades sociales, asimetría en la experiencia sexual... Por 
todo ello, ante una diferencia de edad significativa no se garantiza la verdadera libertad de decisión. Esta asimetría representa en sí misma una coerción.

Por otro lado, Javier Urra (2007: 19) lo complementa con un matiz importante en relación al caso que se expone, al considerar que el abuso sexual no es consentido cuando se realiza en menores de 13 años, ó en personas que se hallen privadas de sentido o con trastorno mental. También puede darse abuso sexual cuando, aún contando con el consentimiento de la víctima, ésta es mayor de 13 años y menor de 16, $\mathrm{y}$ el agresor se ha valido del engaño para viciar el consentimiento del menor.

\section{Secuelas del Abuso Sexual:}

Muchos especialistas igualmente están de acuerdo en que en la gran mayoría de los casos el abuso sexual constituye una experiencia traumática que repercute negativamente en el estado psicológico de las víctimas. Si no se recibe ayuda psicológica adecuada, el malestar suele prolongarse a la edad adulta constituyendo en esta etapa un factor importante de desarrollo psicopatológico. En mi práctica clínica es algo que compruebo cada vez que atiendo personas que siendo menores han sido maltratadas física, psíquica y/o sexualmente. Y generalmente no suelen ser conscientes de la relación que hay entre sus problemas psíquicos actuales y los abusos sufridos hasta que entran a trabajar en su historia emocional.

Los efectos de los abusos sexuales se han intentado explicar desde diversos modelos teóricos desarrollados por los especialistas en la materia. Sobre esto seguimos a Echeburúa y Guerricaechevarria (2000: 41-54), en su estudio de los diferentes modelos explicativos que tratan sobre las repercusiones psicopatológicas del abuso sexual. Ellos destacan que los modelos teóricos más utilizados para explicar el desarrollo de la sintomatología vinculada al abuso sexual han sido, por un lado, el modelo del trastorno de estrés postraumático y, por otro, el modelo traumatogénico. En relación al primero, señalan que el abuso sexual en la infancia cumple los requisitos de trauma exigidos por el DSM-IV para este cuadro clínico y genera, al menos en una mayoría de las víctimas, los síntomas característicos de dicho trastorno. En el seguimiento de las secuelas que se han ido detectando en el paciente, y utilizando la tabla 3.2 de los mismos autores (2000: 46) sobre las Principales consecuencias a corto plazo del abuso sexual en niños y adolescentes (Echeburúa y Guerricaecheverría, 1998), podemos hacer el siguiente resúmen de las mismas:

* Emocionales: Miedo y desconfianza generalizados, depresión, ansiedad, culpa, vergüenza, distorsiones cognitivas, desconfianza, irritabilidad, baja autoestima y sentimientos de estigmatización, rechazo del propio cuerpo, trastorno de la personalidad, dificultad para expresar o recibir sentimientos de ternura y de intimidad, trastorno de estrés postraumático.

* Conductuales: Bajo rendimiento académico, conductas autolesivas y suicidas.

* Físicas: Alteraciones del sueño, problemas gastrointestinales.

* Sociales: Problemas en las relaciones interpersonales, retraimiento social.

* Sexuales: Problemas de identidad sexual, disfunciones sexuales, dificultad para establecer relaciones sexuales. 
Por otro lado, actualizando la información que aporta el DSM-5, Manual diagnóstico y estadístico de los trastornos mentales, de la American Psychiatric Association, sobre el Trastorno de Estrés Postraumático (TEPT), que se editó dos años después de la exploración que realicé al paciente basándome en el DSM-IV, y revisando el estudio realizado por María Crespo y M. Mar Gómez (2016: 161-166), sobre la Concordancia diagnóstica entre DSM-IV y DSM-5 para el Trastorno de Estrés Postraumático (TEPT) en una muestra clínica, no encuentro nada relevante que aportar a las secuelas que ya se detallan anteriormente. Dichas autoras concluyen en su trabajo que existe una alta concordancia entre las clasificaciones para el diagnóstico de TEPT, siendo las diferencias en el diagnóstico debidas fundamentalmente a la nueva conceptualización del criterio C (evitación) y del criterio D (alteraciones negativas cognitivas y del estado del ánimo) en el DSM-5.

Pero más allá de la relación detallada de secuelas que pueden ser causadas por un TEPT, podemos contemplar qué significa esto de las secuelas, visto en el conjunto de la vida de una persona. Para ayudarnos a comprender más en profundidad, y de forma generalizada, la devastación personal que puede suponer vivir en una situación traumática prolongada, veamos lo que dice Judith Herman, (2004: 144-145), psiquiatra y directora de formación del Programa de Víctimas de la Violencia en el Cambridge Hospital:

Las personas que han estado sometidas a un trauma prolongado y repetido desarrollan una forma de desorden de estrés postraumático progresiva e insidiosa que invade y erosiona la personalidad. Mientras que la víctima de un único y agudo trauma puede sentir que, después del acontecimiento, no es 'ella misma', la víctima de un trauma crónico puede sentir que ha cambiado irrevocablemente, o puede perder para siempre la sensación de su propio yo. ... Las personas crónicamente traumatizadas ya no tienen un estado básico de calma física o paz. Con el paso del tiempo perciben que sus cuerpos se han vuelto en su contra. Empiezan a quejarse no sólo de insomnio y agitación, sino también de numerosos tipos de síntomas somáticos.

\section{Los talleres grupales de arteterapia}

A lo largo del proceso de trabajo individual, Juan va participando paralelamente en diferentes talleres grupales de arteterapia. Estos talleres están estructurados en módulos de unas 18-20 sesiones que se realizan durante 6 meses en formato de pequeño grupo, de entre 8 y 10 asistentes. Los participantes son pacientes de terapia individual y personas interesadas en el Arteterapia y en el crecimiento personal. El planteamiento básico de los talleres, una vez enmarcado el significado de esta disciplina, se basa en una propuesta para desarrollar la capacidad creativa, el autoconocimiento y la búsqueda de la salud. Se propone un proceso de expresión artística con el objetivo de facilitar la toma de conciencia y de comprensión de uno mismo. Se ofrece un espacio compartido en grupo donde poder acercarse de forma consciente a las imágenes que se producen, ampliando así la capacidad de verse a uno mismo desde otra perspectiva, de escucharse y expresarse. El proceso arteterapéutico genera a menudo posibilidades sorprendentes para afrontar conflictos internos, o determinadas 
situaciones vitales, y permite desarrollar actitudes de vida promotoras de un mayor cuidado y bienestar integral. Para ello nos servimos de diferentes vías expresivas (plásticas, corporales, musicales, meditativas, narrativas o dramáticas).

Arteterapia es una disciplina joven en nuestro país, y todavía mucha gente no sabe en qué consiste o la confunden con las manualidades artísticas. Por ello, cada vez se hace más necesario aprovechar las posibilidades de difusión social y apoyarse en los estudios de investigación que se publican, que facilitan demostrar y visibilizar su validez en los diferentes ámbitos en que se practica. Miquel Izuel (2012: 14), señala la importancia de potenciar la investigación y la publicación con el objetivo de consolidar los avances, distribuir el conocimiento y mejorar las prácticas desarrolladas. Lo cual permitirá generar confianza, reconocimiento social y redes de conocimiento que contribuyan a la evaluación y la divulgación de los conocimientos relacionados con la disciplina. En este sentido vemos que cada vez se publican más trabajos de investigación, aunque lentamente, porque hemos de reconocer que hay un sector grande, -especialmente entre los que llevamos décadas de práctica profesional, en mi caso mucho más amplia dicha práctica en el ámbito clínico de psicoterapia que en el del arteterapia-, que nos hemos centrado en nuestro trabajo cotidiano de la consulta privada, y no hemos prestado la suficiente atención a este tema, por no haber desarrollado una mentalidad educada hacia la investigación.

En relación al caso que nos ocupa, me ha interesado consultar el trabajo publicado por Pilar Ma Domínguez Toscano (2013: 49-84), donde realiza un análisis bibliográfico de las investigaciones en torno al arteterapia llevadas a cabo en el ámbito de la salud mental y me centro en el apartado de la depresión y la influencia en su tratamiento con arteterapia, pues como hemos visto, nuestro paciente Juan, llegó a terapia con una grave depresión. Así pues, la Doctora Domínguez nos comenta lo siguiente en los apartados de Depresión en etapas vitales críticas y Depresión por situaciones externas traumáticas:

De los 34 informes sobre evaluaciones de programas arteterapéuticos, en 31 se afirma o muestra (según el tipo de estudio) la eficacia de la arteterapia en el tratamiento de la depresión, como terapia única (en la mayoría de las intervenciones) o complementaria. ...En cuanto a los aspectos de la creación artística que mejor justifican su función terapéutica, la práctica totalidad de los documentos mencionan la acción expresiva como el núcleo de la dimensión curativa del arte. De ahí, probablemente, su eficacia en el afrontamiento de la depresión, dado que la alexitimia (o dificultad en la identificación y expresión de las propias emociones) es un rasgo distintivo de la personalidad depresiva y la depresión endógena. Paralelamente, los bloqueos en la expresión se constituyen en uno de los síntomas característicos del estado deprimido, en las depresiones exógenas....El conjunto de los documentos revisados ofrece una panorámica muy alentadora para el uso de la arteterapia en el tratamiento de la depresión.

Y volviendo a nuestros talleres grupales, y a nuestro paciente, Juan, en las primeras sesiones le resulta muy difícil abrirse e integrarse, debido al lastre que cargaba de todo lo anteriormente relatado, pero poco a poco se va soltando y van surgiendo imágenes que le ayudan a visibilizar con más claridad lo que se moviliza a nivel interno. Esto le permite avances y tomas de conciencia esenciales en su evolución personal. Siempre me parece 'mágico', fascinante, el efecto poderoso de una imagen 
en el proceso terapéutico. Ser testigo de cómo mediante las imágenes, el paciente se puede distanciar de sus conflictos internos y, a modo de espejo, reflejarse de forma no amenazadora, para ir creando puentes hacia lo más difícil de mostrar. Lo innombrable. En el campo de las experiencias traumáticas, el relato sobre la violencia no surge fácilmente, ocurre cuando ya se ha construido un vínculo y una confianza con el/la terapeuta. Cuando el paciente se siente acogido, escuchado, comprendido, y hay una seguridad constatada en el marco que le sostiene.

Veamos algunos de los trabajos de estos cinco años:

En un trabajo con la máscara en su primera época de sesiones de arteterapia grupal (año 2012), comenta que a medida que se mete en el trabajo se pone mal porque ha sentido una rabia contenida y mucha tristeza. Se le ve conteniendo las lágrimas. ¿Qué expresa la máscara?.. ¿Qué necesitas ahora?' 'Un abrazo', dice, y rompe a llorar. Algunos compañeros se acercan a abrazarle. Alguien comenta que gracias a él todos se han acercado un poquito más entre sí.

En un trabajo con las emociones, le surgen imágenes de sangre, barrotes, recuerdos de experiencias precoces... 'me siento cansado pero con ganas de cambio.. las huellas del camino están ahi....' Alguien le pregunta sobre las lágrimas que hay pintadas y él responde que son lágrimas de sangre por los abusos sexuales que sufrió ...silencio... alguien le da las gracias por compartirlo.

En el siguiente taller, continuando con el trabajo anterior sobre las emociones le surge pintar una rama de un árbol, ennegrecida porque se muere, se va deshaciendo, en referencia a su sentimiento de soledad y sentirse roto por dentro. Se habla en el grupo de la necesidad de renovarse, de dejar morir aspectos viejos, pesados, el árbol es mucho más que la rama negra. '¿Y si miras el resto del árbol, qué puedes ver?'.

Abordando el tema de los miedos (2014) aprovecha para comentar que le gusta venir al taller porque siente que respira de otra manera y puede expresar cosas que fuera sería imposible. Habla de los distintos temores que tiene, que le superan y arrastran. En la propuesta de ver qué quiere hacer con esos miedos, emerge una forma de paloma en papel verde que ha superpuesto encima de la pintura. ¿Cómo puedes aplicar esto en tu vida cotidiana? ¿Qué quieres ó puedes hacer para estar bien? ¿Puedes ponerte en el lugar de la paloma? ¿Qué dice sobre esos miedos? El verde, dice, es la esperanza, que vuela sobre sus miedos y le permite verlos a distancia, relativizarlos y sentirse mejor.

En la sesión siguiente continúa con los miedos. Habla del miedo a conocerse a sí mismo. Después, en la siguiente sesión de terapia individual trae el tema para abordar lo que no pudo compartir con el grupo en relación a su historia con el señor $\mathrm{X}$. Va desgranando algunos miedos y observa la influencia que han tenido en que permaneciera 25 años con X. Estos años los siente como un pasado 'perdido' en su vida, pero también comprende que no era consciente entonces. ¿Qué quieres/qué necesitas hacer con todo eso? Quiere aprender a darles la vuelta, relativizarlos, soltarlos. Aprovechar mejor lo que tiene aquí y ahora.

El tema de los miedos sigue apareciendo en varias sesiones grupales y los va trayendo al espacio individual. Los miedos le llevan a cuestionarse que quizás no sea 'del todo heterosexual'. Quizás tenga que empezar a averiguar cuál es su orientación sexual. Le da pánico pensar en que si llega a la conclusión de que es homosexual, tendría que afrontar una serie de consecuencias que no se ve con fuerzas. Al hacerse 
más consciente de cómo todo esto le oprime y desgasta decide por fin que se quiere liberar. Habla con su mujer sobre sus dudas y se lleva una sorpresa con su respuesta, pues ella ya sospechaba algo de eso. Se queda sorprendido de cómo se resuelve el tema tan fácilmente, en contraste con lo mal que lo ha pasado.

En otra sesión grupal se trabaja con la idea de visualizar un animal salvaje que queda atrapado en una trampa. El animal ha de buscar la forma de liberarse. Él visualiza un lobo atrapado en una red de alambres. Ha de luchar con mucho coraje para librarse y lo consigue pero sale malherido y ha perdido una 'pierna' (lapsus). ¿Cómo se siente el lobo al librarse? - 'Mucha alegría de volver a sentirse libre'- ¿Qué hace con sus heridas? - 'Se va curando y aprende a vivir sin la pata'-. Juan se siente muy angustiado con el lobo atrapado al verse representado a sí mismo y conectar con su lado de impotencia. Ante su tendencia automática a fijarse en lo negativo, le planteo si puede dejar su angustia a un lado y dejarse 'sentir' cómo es la sensación del lobo de alegría y libertad por haberse podido librar del peligro.

En el último y reciente módulo de arteterapia grupal, realizado de Enero a Junio de 2017, se empiezan a ver cambios significativos:

En un trabajo de Collage sobre uno mismo, le llama la atención una foto de terroristas, 'por la violencia que también ha habido en mi vida; también me llama la atención la cara de un hombre que expresa una emoción. Siempre he sido muy introvertido y reservado y me cuesta mucho expresar las emociones. Estoy aprendiendo a observar y cuidar mis emociones y sentimientos'.

En una obra de opción libre, realiza un paisaje de montaña, con un torrente...- 'Soy una persona que vive su apertura consciente a la vida. ¿Qué puedo hacer frente a mí mismo? ¿Cómo vivir con mi consciencia, con mi vida, a veces tan extraña a mí?-’. ¿Con qué te quedas de esta experiencia?', - 'Me quedo con lo de aceptar lo que uno está sintiendo, sin ahogarse en el torrente de nuestras emociones...

A través de un trabajo de impresión por medio de un pliegue, percibe una forma armoniosa pero destaca que en realidad está muy alterado por una discusión con su pareja. - ¿Por qué lo he hecho así cuando me siento tan mal?...Es porque necesitaba calmarme. . mi capacidad de disimular es grande, de no querer ver el problema hasta que luego sale'-... ¿Y ahora como lo ves? - 'Siento que estoy dando un paso más en mi favor... Ver la manera de sacar, si no sacas no tienes la suficiente perspectiva para poder ver...'-.

En una propuesta de relajación y visualización de un árbol, al describirlo en primera persona se visualiza como un árbol joven, de raíces profundas, que está en un lugar privilegiado de la montaña, con una vista amplia y extensa. Está sorprendido de todo lo positivo que ve en su árbol, refleja el momento en que se encuentra ahora, mucho mejor.

En un trabajo de opción libre, recupera la idea de la máscara: 'Lo desfigurado es que se está rompiendo internamente, pero es una ruptura positiva, para ir a mejor, para no quedarme con lo malo toda la vida, para superarme, es un proceso interior. Algunas cosas se han de romper, y se romperán para que sobreviva... 'Esta máscara de 2017 es muy diferente de la que pintó en 2012, tanto en la forma plástica como en lo que representan para el paciente cada una de ellas. 


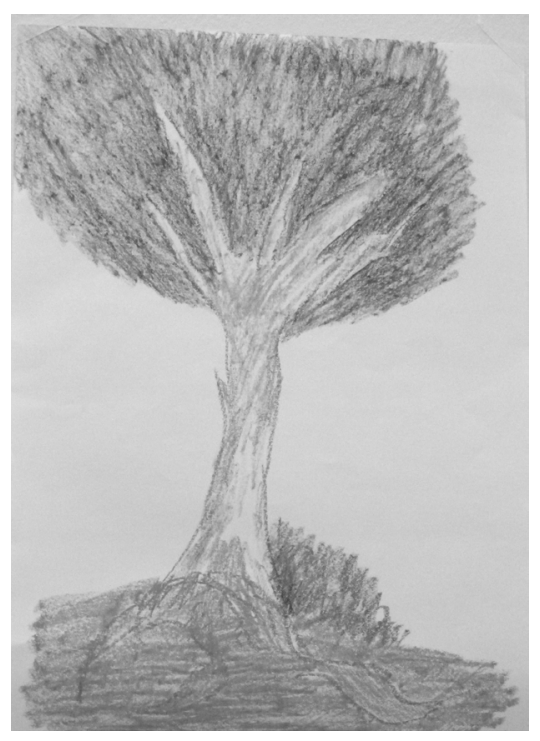

Dibujo 'El árbol'

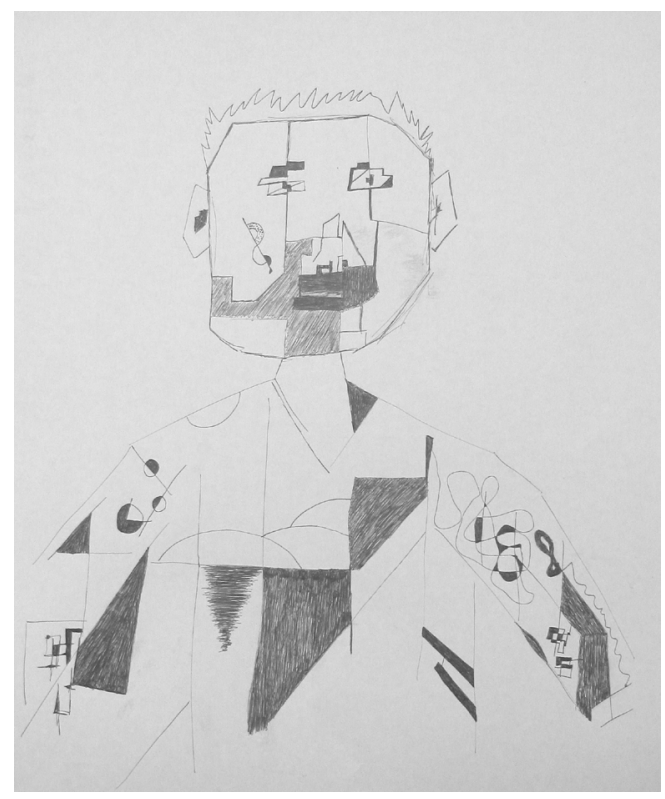

Dibujo 'La máscara de 2017'.

El último taller de arteterapia finalizó hace dos meses, y en los comentarios sobre la valoración del proceso grupal, Juan nos dice: "Llegué con ganas... Durante el proceso ha habido momentos de lucha interior y de descubrimiento... Ha habido días de auténtico dolor pero con crecimiento. Me voy más fuerte... He aprendido a no olvidarme de mi mismo ante todo, buscando lo bueno de la vida en mí... Y aceptándome con los bajones...". 


\section{Trabajo con la comprensión y el perdón.}

Paralelamente a los talleres de arteterapia, y a medida que Juan avanza en su proceso y puede discernir y trabajar por separado con las diferentes emociones que siente asociadas a esta relación con el señor X, se va formando una visión más clara, completa y comprensiva de sí mismo. Ha necesitado expresar -verbalmente y a través de medios artísticos- recuerdos, pensamientos, emociones, creencias, ha transitado por su historia personal, y tiene una perspectiva más realista de la relación mutuamente dependiente y enfermiza que desarrolló junto al señor X. El trastorno de estrés postraumático derivado de los abusos se viene a sumar a una infancia muy difícil para él, donde había otras violencias y otros traumas que ya estaba sufriendo desde muy pequeño y que le llevaron a una vulnerabilidad extrema.

Juan empieza a ver al señor $\mathrm{X}$ con otros ojos, como una persona enferma, probablemente con una historia de víctima a su vez, como sucede con la mayoría de los agresores, -según diversos estudios que se publican al respecto-, atrapado en una homosexualidad reprimida y oculta en una doble vida. Le consta que fue un infierno también para él, y buscaba consuelo a su 'enfermedad' asistiendo a los oficios religiosos varias veces al día, confesándose a diario y obligándole a confesarse a él también. Puede reconocer que el señor X en realidad fue, antes que su agresor, el 'padre' afectuoso y protector que necesitaba, manteniéndose este rol a lo largo de toda la relación. Eso sí, bajo una espesa capa de amor-odio.

En relación a este vínculo de amor-odio, recuerdo algo que ya comenté en un artículo anterior, sobre un caso de violencia de género y arteterapia (Ascaso, P. 2012, 223-244). Era en relación al amor y la violencia, y el comentario se ajusta perfectamente a este caso. Citaba a Pepa Horno (2009), cuando se refiere a las creencias que tenemos en nuestra sociedad, muy polarizadas en el sentido de asociar la violencia a un sentido destructivo, y el afecto como algo positivo. Y señala que esta visión está idealizada, pues en el afecto también puede haber manipulación, engaño y daño. Hay afectos que destruyen sin dejar de ser afectos. Por ello, cuando el vínculo afectivo se ha hecho muy potente, y deriva hacia lo violento, convirtiéndose en un eje importante de la relación, acaba atrapando y esclavizando a muchas personas en una espiral de violencia, de amor-odio, de la cual y por diversos motivos que no procede tratar aquí, no encuentran la forma de salir.

Las revelaciones que van surgiendo en la comprensión de sí mismo, permiten a Juan empezar a perdonar al señor X, de una forma íntegra, con la mente y el corazón. Le pregunto si quiere hacer algo con todo esto y surge la idea de escribirle una carta simbólica de reconciliación, que le ayuda a 'cerrar' este capítulo y a sentirse mucho más liberado. Alice Miller ((2009: 240-241) en mi opinión enfoca el tema del perdón con una claridad meridiana:

El auténtico perdón no bordea la rabia sin tocarla, sino que pasa a través de ella. Sólo cuando pueda indignarme por la injusticia que cometieron conmigo, cuando advierta el acoso como tal y pueda reconocer y odiar a mi perseguidor como tal, solo entonces se me abrirá realmente la vía del perdón. La ira, la rabia y el odio reprimidos dejarán de perpetuarse eternamente sólo cuando la historia de los abusos pueda ser revelada. Y entonces se transformarán en duelo y en dolor ante la inevitabilidad del hecho, dejando, en medio de ese dolor, cabida a una verdadera comprensión, a la comprensión del adulto que ha echado una mirada a su historia. 
Este perdón no puede ser exigido con preceptos ni mandamientos. Ha de ser vivido como gracia y surgirá espontáneamente cuando ningún odio reprimido -por estar vedado-, siga envenenando el alma. El sol no necesita que le obliguen a brillar, cuando las nubes se apartan, él, simplemente, brilla. Pero sería erróneo ignorar que las nubes constituyen un impedimento cuando realmente se presentan.

Este tránsito de Juan en la búsqueda de su verdad y del perdón le va llevando por el camino de 'reconciliarse' progresivamente consigo mismo. Va comprendiendo la importancia esencial de perdonar y perdonarse, para soltar lastres y poder rehacer su vida con dignidad. Cuando un conflicto es tan hondo y tan crónico en el tiempo, perdonar no es un acto, sino un proceso afectivo, al que se llega la mayor parte de las veces a través de un trabajo personal, pues al estar asociado el conflicto a aspectos de relaciones vinculares muy íntimas y estrechas, puede haber causado heridas muy graves.

En este sentido, Pepa Horno (2009, p. 63) destaca dos niveles fundamentales para que el proceso del perdón pueda darse: integración y reconstrucción. En el primer nivel, la persona es capaz de integrar varias cosas: Lo primero, el dolor y/o el daño que lo sucedido le ha causado. Segundo, la comprensión racional de las causas o factores que han llevado a la persona a hacer lo que hizo, por supuesto diferenciando comprender de justificar, y tercero, la ganancia que se obtiene de no odiar. En el nivel de integración ya se pasa a intentar reconstruir la relación con la persona que generó el daño. Este paso es mucho más complicado y difícil de alcanzar, pero en el caso de Juan, parece que hubiera sido posible, si el señor $\mathrm{X}$ viviera, dadas las circunstancias especiales de esta relación. La carta que le escribió, mencionada anteriormente, iba en esta dirección.

Así pues, Juan se encuentra en un punto muy evolucionado de su proceso. La rabia y el rencor se han diluido. El duelo se ha procesado y ha entrado en una comprensión más profunda, donde esta historia prácticamente no le duele. Queda la herida. Siempre será importante la huella que una experiencia así deja, pero puede mirarla con una distancia mayor, y pasar página para mirar hacia adelante.

De ahí emerge la necesidad de acercarse a sus padres y hablarles de su historia oculta. Le acompaño en la preparación de este encuentro, que piensa y escribe muy cuidadosamente. Los padres, ya mayores, reaccionan mejor de lo que él esperaba. Al conseguir derribar este 'muro' se siente más abierto y cercano a ellos, puede mirarles a los ojos, demostrarles su cariño. Siente que les ha 'recuperado' y se observa un gran cambio en su energía vital.

El siguiente paso surge por su necesidad de buscar el perdón espiritual, de 'recuperar también su alma'. Se le ocurre que puede enviar una carta al Papa Francisco, explicándole la historia y pidiendo el perdón para el señor X y también para él. Le acompaño en su preparación y la remite al Vaticano sin preocuparse de recibir respuesta, al entender que lo importante es el hecho de haberla redactado y enviado.

A medida que se encuentra mejor y ya no se siente tan poseído por su pasado traumático, podemos empezar a abordar otros aspectos relacionados con sus fortalezas, poniendo la atención en lo que valora de su persona y de su vida actual. Cada vez emerge con más fuerza el extraordinario potencial creativo que posee, tanto a nivel artístico, como narrativo y poético. Su mirada se va girando del pasado al presente y se abre al futuro con más confianza y menos miedo. 


\section{Conclusiones}

En este intenso proceso de seis años, Juan ha hecho una evolución y avances notables, entre ellos destacamos los más 'medibles':

* Empezamos este viaje con un diagnóstico psiquiátrico grave, intentos de autolisis, y obsesiones compulsivas autodestructivas. La fuerte batería de psicofármacos que tomó durante años ha quedado reducida a no tomar nada desde hace un año.

* Pasó dos años consecutivos de Baja Laboral por enfermedad. Posteriormente las Bajas se han ido espaciando de forma progresiva hasta desaparecer. En la actualidad lleva un año y medio sin estar de baja.

* Su adicción a la pornografía ha disminuido notablemente, organizando su tiempo de forma más práctica y positiva.

* Las ideas obsesivas y el sufrimiento que le conllevan han pasado de ser una 'pesadilla mental constante' a minimizar y relativizar su impacto y poder concentrarse mejor en sus tareas y en el presente. La práctica de meditación que hemos incorporado gradualmente también ha resultado de gran ayuda en la forma cómo se relaciona con sus contenidos mentales.

* Su orientación sexual sigue en observación, asumiendo de momento que es bisexual y dejando al aire el interrogante de si realmente es homosexual.

* Al encontrarse más centrado y estable, es posible ir trabajando desde hace un tiempo en los aspectos positivos de sí mismo, en sus fortalezas. Como él afirma 'Sintiendo que puede poner los pies en la tierra, puede enraizarse en relación a ese abismo que se sigue abriendo ante sus ojos, aunque ahora ya no tan amenazador'.

* Actualmente, y finalizado el ultimo taller de arteterapia, Juan continúa en su proceso, únicamente ya con sesiones individuales, que son cada vez más esporádicas.

\section{Algunas reflexiones}

En vista de lo que acabamos de ver en las conclusiones, es evidente que, a día de hoy, el paciente presenta una mejoría que me permito decir 'espectacular'. Por este motivo he presentado este caso, asombrada de los resultados, pues he de confesar que en los primeros tiempos del proceso no albergaba muchas esperanzas y continuamente me preparaba para lo peor. Ha habido momentos muy difíciles, algunos retrocesos duros, han surgido dudas, temores, inseguridades, preguntas del tipo ¿Pueden hacerse realidad sus temores y llegar a ser realmente un abusador de niños?, (trabaja con ellos a diario). ¿Hasta qué punto puede haber un peligro de perversión? ¿Se hará realidad su ideación suicida?, etc.

Sin embargo, y por encima de todo lo anterior, me ha sido posible sostener una actitud afectuosa de aceptación y escucha incondicional, de esperanza y confianza en su capacidad de crecimiento y sanación. Me ha ayudado mucho poder mantenerme en el corazón, sin perder de vista la cabeza y el marco terapéutico. En este sentido, me gusta ver este proceso como una relación de 'maternaje' simbólico, que se ha 
sostenido a través de una actitud de 'compromiso' mutuo, de estar ahí, y creo que esto ha sido fundamental para llegar a donde hemos llegado. Comprometerse profundamente no garantiza el éxito en una relación de dos, ni garantiza sus resultados, pero ayuda más que cualquier otro factor a asegurarla. Y en relación a este maternaje, desde hace un tiempo parece que hay un 'adolescente' que quiere volar porque ya confía más en sus propias fuerzas, en su poder personal. Mejor dicho, creo que muy pronto este 'adolescente/adulto' alzará el vuelo y se 'independizará' de esta relación terapéutica para vivir su vida de una forma más autónoma y responsable. Reconectado y reconciliado consigo mismo y con los demás.

Por todo ello, viendo cómo llegó y cómo se encuentra actualmente, me parece también un caso espectacular de resiliencia. Este concepto se refiere básicamente a la capacidad de resistencia que puede tener un ser humano frente a la destrucción, y a la capacidad para reconstruir su propia vida. Como dice Boris Cyrulnik (2001), 'ninguna herida es irreversible siempre que se pongan en su sitio los mecanismos de defensa y que se le tiendan las manos a la persona afectada'. Así pues, un niño herido no está condenado a convertirse en un adulto fracasado. Es posible la esperanza de ver al patito feo convertido en cisne, especialmente cuando se unen tres factores importantes que influyen en el desarrollo de la resiliencia, como son la capacidad de vincularidad, la creatividad y el sentido del humor.

La combinación paralela de la psicoterapia individual con el trabajo grupal de arteterapia ha permitido a Juan avanzar de forma más consistente en su proceso de autoconocimiento, de elaboración cognitiva y emocional de sus conflictos, de reintegración a la vida social. Ha favorecido un notable desarrollo de su capacidad creativa a través de la creación artística. Ha podido acercarse a rincones oscuros de su mundo interior, les ha puesto luz, les ha dado voz, generando una comprensión que le ha ayudado a observar, reestructurar, asumir e integrar de forma más realista y constructiva su historia personal y su visión de sí mismo.

A nivel personal-profesional, el arteterapia me ha facilitado llegar a una comprensión más profunda de la gran dificultad que puede haber al intentar transmitir en palabras la envergadura del sufrimiento que puede llegar a experimentar una persona a lo largo de tantos años de silencio y hermetismo. El arteterapia ha sido de una ayuda inestimable en este proceso, poniendo una imagen allá donde no llegan las palabras y ayudando a que emerja a la superficie lo que no se sabe, o no se puede, explicar.

En definitiva, la curación siempre es un duro y largo proceso de esfuerzos, como suele ser casi toda terapia profunda. Curarse empieza por afrontar y aceptar la enfermedad mental, con todo lo que conlleva, y por tanto aceptar la responsabilidad de sí mismo. Como dice M. Scott Peck (293-294):

Quienes han afrontado su enfermedad mental, han aceptado su total responsabilidad y se han aceptado a sí mismos para superarla, se encuentran no sólo curados y libres de las maldiciones de su niñez y de sus antepasados, sino también viviendo en un mundo y diferente. Lo que antes percibían como problemas, les parecen ahora oportunidades; lo que antes eran pesadas barreras, son ahora emociones gratas; los pensamientos que antes eran desagradables, se convierten en intuiciones útiles; los sentimientos que antes repudiaban, son ahora fuentes de energía y de orientación...

Para acabar sólo me queda por añadir que siento una agradecida emoción de poder compartir esta historia. Es un privilegio para mí haber podido acompañar a Juan todo este tiempo y ver los frutos de este trabajo, valorarlos con él, admirarlos, admirarle, por su coraje, por su perseverancia y por su compromiso. Un gran y especial 
regalo ha sido verle sonreír en los últimos meses, como nunca antes le había visto, compartiendo con él risas y bromas. Y bueno, en definitiva, en su lucha entre Eros y Tanatos parece que al final se impone la vida, se impone el amor.

\section{Bibliografía}

Ascaso, P. (2012). Quiero y no puedo. De las resistencias y los límites en un proceso de arteterapia grupal y violencia de género a través del seguimiento de un caso. Revista Arteterapia. Papeles de Arteterapia y Educación Artística para la inclusión social. Publicaciones Universidad Complutense de Madrid. Vol. 7/2012.

Cyrulnik, B. (2002). Los patitos feos. La resiliencia: una infancia infeliz no determina la vida. Gedisa.

Crespo, M. y Gómez, M.M. (2016) Concordancia diagnóstica entre DSM-IV y DSM-5 para el Trastorno de Estrés Postraumático (TEPT) en una muestra clínica. Psicothema, Vol. 28, No. 2, (161-166).

Domínguez Toscano, P.M. (2013). Arteterapia en el tratamiento de la depresión. Revisión de la producción cientifica, en Estéban Arbués, A. y Garrido Muñoz de Arenillas, Mª (Coord.) Arteterapia en el ámbito de la salud mental, (49-84). https://www.researchgate. net/publication/264401256

Echeburúa, E. y Guerricaechevarría, C. (2000). Abuso sexual en la infancia: víctimas y agresores. Un enfoque clínico. Ariel.

Herman, J. (2004). Trauma y Recuperación. Cómo superar las consecuencias de la violencia. Espasa Hoy.

Horno, PEPA. (2009). Amor y violencia. La dimensión afectiva del maltrato. Desclée de Brouwer.

Izuel, M. y Vallès, J. (2012). Competencias profesionales en investigación y arteterapia. Revista Arteterapia. Papeles de Arteterapia y Educación Artística para la inclusión social. Publicaciones Universidad Complutense de Madrid. Vol. 7/2012.

Miller, A. (2009). Por tu propio bien. Raíces de la violencia en la educación del niño. Emsayo Tusquets.

Save the Children. (2001). Abuso Sexual Infantil: Manual de Formación para Profesionales.

Save the Children/Ministerio de Trabajo y Asuntos Sociales.

https://www.savethechildren.es/sites/default/files/imce/docs/manual_abuso_sexual.pdf

Scott Peck, M. Un camino sin huellas. La nueva psicología del amor. Emecé.

Urra Portillo, J. (2007). SOS... Víctima de abusos sexuales. Pirámide. 